\title{
Alveolar bone loss in relation to toll-like receptor 4 and 9 genotypes and Porphyromonas gingivalis carriage
}

\section{Gursoy, Ulvi}

\author{
2016-11
}

Gursoy , U , He , Q , Pussinen , P , Huumonen , S \& Könönen , E 2016 , ' Alveolar bone loss in relation to toll-like receptor 4 and 9 genotypes and Porphyromonas gingivalis carriage ' , European Journal of Clinical Microbiology \& Infectious Diseases , vol. 35 , no. 11 , pp. 1871-1876 . https://doi.org/10.1007/s10096-016-2741-6

http://hdl.handle.net/10138/229280

https://doi.org/10.1007/s10096-016-2741-6

publishedVersion

Downloaded from Helda, University of Helsinki institutional repository.

This is an electronic reprint of the original article.

This reprint may differ from the original in pagination and typographic detail.

Please cite the original version. 


\title{
Alveolar bone loss in relation to toll-like receptor 4 and 9 genotypes and Porphyromonas gingivalis carriage
}

\author{
U. K. Gursoy ${ }^{1}$ • Q. He $^{2}$ • P. Pussinen ${ }^{3}$ • S. Huumonen ${ }^{4,5}$ • E. Könönen ${ }^{1,6}$
}

Received: 30 May 2016 / Accepted: 24 July 2016/Published online: 4 August 2016

(C) Springer-Verlag Berlin Heidelberg 2016

\begin{abstract}
Toll-like receptors (TLRs) are highly developed sensors to detect microbe-associated molecular patterns. Functional polymorphisms of the genes TLR 4 and TLR 9 were found to be associated with alveolar bone loss in a Porphyromonas gingivalis-induced periodontitis model in mice. Our aim was to examine whether such an association can be detected in a group of Finnish adults. Polymorphisms of TLR4 Asp299Gly (rs4986790) and TLR9 rs187084 (1486 $\mathrm{T} / \mathrm{C}$ ) were genotyped by pyrosequencing and PCR from the saliva samples of 223 adults (age range 40-60 years). Alveolar bone loss, measured from panoramic radiographs, were compared between TLR genotype groups according to subjects' salivary carriage of $P$. gingivalis, measured using a single copy gene-based real-time PCR. The frequencies of TLR 4 wild type and heterozygote variants were $87.4 \%$ and $12.6 \%$, respectively, while those of TLR 9 wild type, heterozygote, and homozygote variants were $25.6 \%, 39.1 \%$, and
\end{abstract}

U. K. Gursoy

ulvi.gursoy@utu.fi

1 Department of Periodontology, Institute of Dentistry, University of Turku, Turku, Finland

2 Department of Medical Microbiology and Immunology, University of Turku, Turku, Finland

3 Department of Oral and Maxillofacial Diseases, University of Helsinki, Helsinki, Finland

4 Department of Oral Radiology, Institute of Dentistry, University of Turku, Turku, Finland

5 Department of Diagnostic Imaging, Turku University Hospital, Turku, Finland

6 Oral Health Care, Welfare Division, City of Turku, Turku, Finland
$35.3 \%$, respectively. In the TLR4 heterozygote group, $P$. gingivalis-positive subjects had more alveolar bone loss than $P$. gingivalis-negative subjects $(p=0.027)$, while no difference was observed in the wild type group. $P$. gingivalis-negative individuals with TLR9 heterozygotes exhibited significantly less alveolar bone loss compared to those with TLR9 wild type $(p=0.007)$. Polymorphisms of TLR4 in P. gingivalis carriers seem to expose to alveolar bone loss. Polymorphisms of TLR 9 can be protective against alveolar bone loss in the absence of $P$. gingivalis.

\section{Introduction}

Periodontitis is a chronic inflammatory disease of toothsupporting tissues induced by pathogenic bacteria, which are often found in biofilms attached to tooth surfaces $[1,2]$. Periodontitis is a polymicrobial disease, where Porphyromonas gingivalis, a Gram-negative anaerobic bacterium, acts as a pathogen and promotes dysbiosis by regulating the biofilm composition qualitatively and quantitatively [3]. Moreover, several virulence factors of this periodontopathogen, i.e., gingipains and lipid A phosphatases, can activate or inhibit innate and adaptive immune responses of the host [4]. Although the carriage of $P$. gingivalis does not necessarily predict the development or presence of periodontitis, it indicates an increased risk for periodontitis in susceptible subjects [5].

Host innate and adaptive immune response mechanisms use pattern recognition receptors (PRR) to sense microbeassociated molecular patterns. Among the PRRs, toll-like receptors (TLRs) are the most studied ones. Up to now, ten TLRs (TLR1-10) have been characterized in humans. TLR1, TLR2, TLR4, TLR5, TLR6, and TLR10 are located on cell membrane, while TLR3, TLR7, TLR8, and TLR9 reside in 
endosomes [6]. Against the constant challenge of bacteria present in the oral cavity, resident cells activate innate immune response via TLR-dependent mechanisms [7]. Periodontal ligament cells and gingival tissue cells can recognize bacterial lipopolysaccharides (LPS) by their TLR4 [8, 9] and bacterial DNA by endoplasmic TLRs [10]. During periodontal infection, there is an increased TLR gene expression leading to elevated protein levels [11, 12]. Nevertheless, when bacterial LPS is detected by TLR, it does not necessarily result in a successful elimination of the pathogen and suppression of the disease by immune response. For example, LPS impairs the differentiation of periodontal ligament stem cells to osteoblasts through the activation of TLR4, disturbing new bone formation [9].

In knock-out mice models, it was observed that disturbances in function of TLR4 and TLR9 may cause disrupted immune response against $P$. gingivalis, which can lead to impaired inflammatory response and, eventually, alveolar bone loss [13-15]. To our knowledge, only two studies have demonstrated simultaneous interactions of $P$. gingivalis and TLR4 single nucleotide polymorphism (SNP) with periodontitis [16, 17]. Concerning TLR9, the findings of mice studies have not been confirmed in humans. In the present study, we hypothesized that being positive for $P$. gingivalis is a risk factor of advanced alveolar bone loss in subjects with functional polymorphisms of TLR4 and TLR9. Therefore, we aimed to determine the associations between carriage of $P$. gingivalis, functional polymorphisms of TLR4 and TLR9, and alveolar bone loss.

\section{Material and methods}

\section{Salivary samples}

Salivary samples originated from 223 subjects (part of the national Finnish health survey Health 2000), and their information came from the data on questionnaires, interviews, and clinical health examinations. All participants gave a written informed consent, and study protocols were approved by the Ethical Committee for Epidemiology and Public Health of the Hospital District of Helsinki and Uusimaa, Finland.

Paraffin-stimulated whole saliva samples had been collected into Eppendorf tubes, which were transported in carbonic acid ice and immediately frozen at $-70{ }^{\circ} \mathrm{C}$ until further use. When the saliva samples were thawed for the first time, they were centrifuged at 10,000 rpm for $5 \mathrm{~min}$, and the pellets were used for the assays of genotyping and microbiology.

\section{Genotyping}

For the present study, the genotyping of TLR4 Asp299Gly (rs4986790) from saliva was performed by pyrosequencing

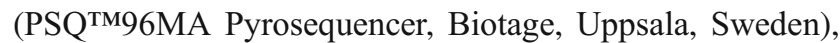
using the PSQTM96 Pyro Gold Q96 reagent kit according to the manufacturer's instruction as described previously [18]. TLR9 rs187084 (1486 T/C) genotyping was performed [19] by using BspTI restriction enzyme (ThermoFischer Scientific, Waltham, USA) for digestion of the PCR product.

\section{Microbiological analysis}

Salivary $P$. gingivalis levels were available from our previous study [20]. The analysis was performed using a single copy gene-based real-time PCR as published in detail [21]. The viability or salivary levels of $P$. gingivalis were unknown to the researchers at the time of the saliva collection.

\section{Radiographic analysis}

Alveolar bone loss (Fig. 1) was measured from radiographs that were taken with a dental panoramic X-ray machine (PM 2002 CC proline apparatus, Planmeca, Helsinki, Finland) using imaging values between $58-68 \mathrm{kV}$ and $4-10 \mathrm{~mA}$. A specialist in oral and maxillofacial radiology (S.H.) analyzed alveolar bone loss from the digital panoramic radiographs using an inbuilt measuring tool of the Dimaxis software (Planmeca, Helsinki, Finland). The mesial and distal surfaces
Fig. 1 In a periodontally healthy condition (a), the distance between the alveolar bone crest (marked with an arrow) and cementoenamel junctions of neighbouring teeth (marked with a dashed line) is about $2 \mathrm{~mm}$. With the development of periodontitis (b), alveolar bone loss becomes visible in vertical and/or horizontal forms on radiographs (by courtesy of Güliz N. Güncü, Associate Professor, University of Hacettepe, Ankara, Turkey)
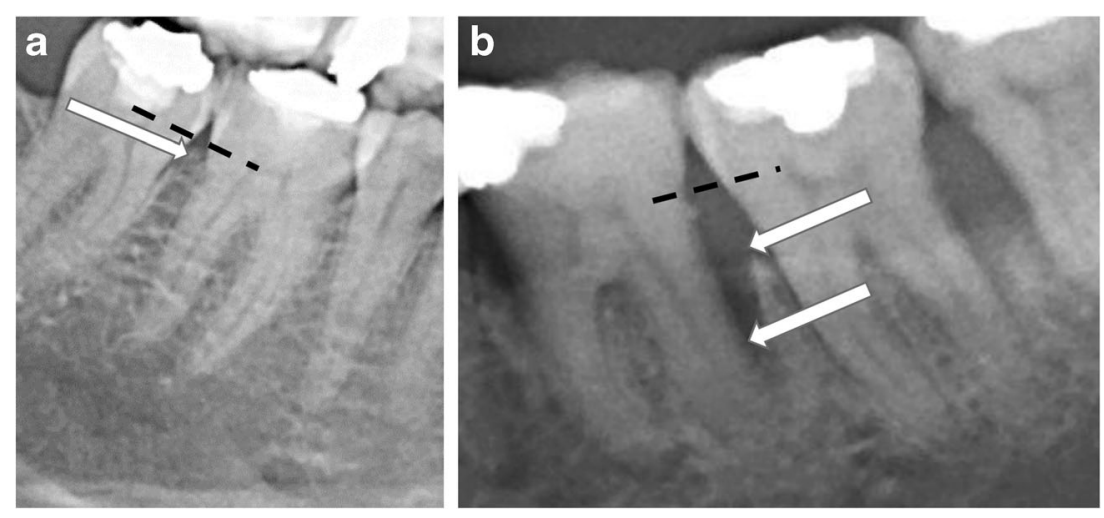
of each tooth and the furcation areas of molar teeth were evaluated. Total alveolar bone loss of a subject was calculated as a sum of horizontal (the distance between the cementoenamel junction and the alveolar bone crest), vertical (the distance from the alveolar bone crest to the bottom of alveolar bone pocket), and furcation (the distance from the furcation to the alveolar bone crest) bone losses. All measurements were recorded in millimeters [22]. The Advisory Board for Radiation Safety approved radiographical examination protocols, and the Radiation and Nuclear Safety Authority and the Ethics Committees for Human Studies of the National Public Health Institute and the Institute of Epidemiology and National Health, Finland granted the safety licenses.

\section{Statistical analyses}

All data analyses were performed with the SPSS statistical program (version 23.0; IBM Armonk, New York, USA). The data distributions of alveolar bone loss were skewed, therefore, non-parametric tests were applied. The KruskalWallis H (for multiple comparisons) and Mann-Whitney U tests were used for comparing alveolar bone loss between the TLR genotype groups. All other parameters were compared with the ANOVA test (with Bonferonni correction). A statistical significance was defined as a $p$ value $<0.05$.

\section{Results}

Of the 223 salivary samples, TLR4 genotypes were determined in all samples, while TLR 9 genotypes were detected in 215 samples. In eight samples, TLR9 genotype was not detected due to the low quality or quantity of saliva samples and their DNA. The frequencies of TLR4 wild type and heterozygote variants were $87.4 \%$ and $12.6 \%$, respectively, while those of TLR 9 wild type, heterozygote, and homozygote variants were $25.6 \%, 39.1 \%$, and $35.3 \%$, respectively.
The distribution of age, gender, the percentage of smokers, number of teeth, alveolar bone loss, salivary levels of $P$. gingivalis, and percentage of $P$. gingivalis carriers did not differ between the genotypes of TLR4 and TLR9 (Table 1). Seventy-three subjects had mild $(0-2.9 \mathrm{~mm}), 74$ subjects had moderate $(3-13.4 \mathrm{~mm})$, and 76 subjects had advanced (over $13.5 \mathrm{~mm}$ ) alveolar bone loss.

In TLR4 heterozygotes, $P$. gingivalis-positive subjects had more alveolar bone loss than $P$. gingivalis-negative subjects $(p=0.025)$. Moreover, among $P$. gingivalis-positive subjects, individuals with TLR4 heterozygotes had elevated alveolar bone loss in comparison to individuals with TLR4 wild type $(p=0.054)$. Alveolar bone loss was not different between the $P$. gingivalis-positive $(n=111)$ and -negative $(n=84)$ subjects with TLR4 wild types (Fig. 2).

Among the $P$. gingivalis-negative subjects $(n=91)$, individuals with $T L R 9$ heterozygotes exhibited significantly less alveolar bone loss in comparison to those with TLR9 wild type (Fig. 3).

\section{Discussion}

In the present study, it was shown that in subjects with TLR4 Asp299Gly (rs4986790) SNP, the carriage of $P$. gingivalis in saliva is related to advanced alveolar bone loss. We also present evidence that TLR9 (rs187084) SNP may be protective against alveolar bone loss in the absence of $P$. gingivalis. Since periodontitis is a multifactorial disease and multispecies-biofilms are responsible for periodontal infection, a single SNP and the presence of a single pathogen cannot fully explain the initiation and development of periodontitis. However, our results can be used to characterize susceptible patients (subjects with TLR4 Asp299Gly SNP and positive for $P$. gingivalis) to define risk groups of periodontitis.

Alveolar bone loss was used as an outcome variable in the present study. The extent of periodontal destruction was then related to TLR polymorphisms and $P$. gingivalis carriage that

Table 1 Characterization of the subjects in TLR genotype groups with age, gender, smoking status, number of teeth, alveolar bone loss, and carriage of $P$. gingivalis

\begin{tabular}{|c|c|c|c|c|c|c|c|}
\hline \multirow[t]{2}{*}{ Characteristic } & \multicolumn{3}{|l|}{ TLR4 } & \multicolumn{4}{|l|}{ TLRO } \\
\hline & $\begin{array}{l}\text { Wild type } \\
(n=195)\end{array}$ & $\begin{array}{l}\text { Heterozygote variants } \\
\mathrm{T} / \mathrm{C}(n=28)\end{array}$ & $p$ value & $\begin{array}{l}\text { Wild type } \\
(n=55)\end{array}$ & $\begin{array}{l}\text { Heterozygote variants } \\
\mathrm{C} / \mathrm{T}(n=84)\end{array}$ & $\begin{array}{l}\text { Homozygote variants } \\
\mathrm{T} / \mathrm{T}(n=76)\end{array}$ & $p$ value \\
\hline Age in years [mean $(\mathrm{SD})]$ & $48.5(5.3)$ & $49.8(5.7)$ & 0.231 & $48.4(6.0)$ & $49.1(5.4)$ & $48.5(5.1)$ & 0.733 \\
\hline$\%$ female & 53.3 & 60.7 & 0.463 & 50.9 & 60.7 & 48.7 & 0.273 \\
\hline$\%$ smokers & 37.9 & 35.7 & 0.954 & 47.3 & 32.3 & 35.5 & 0.478 \\
\hline No. of teeth [mean (SD)] & $26.9(2.4)$ & $26.9(2.6)$ & 0.959 & $27.2(2.4)$ & $26.8(2.5)$ & $26.9(2.3)$ & 0.672 \\
\hline $\begin{array}{l}\text { Alveolar bone loss (mm) } \\
\text { [median (range) }]\end{array}$ & $5.9(196.2)$ & $10.0(183.8)$ & 0.194 & $8.2(113.9)$ & $3.9(196.2)$ & $6.8(184.1)$ & 0.099 \\
\hline$\%$ subjects with Pg & 56.9 & 53.6 & 0.738 & 63.6 & 54.8 & 56.6 & 0.568 \\
\hline
\end{tabular}


Fig. 2 Alveolar bone loss in subjects with wild type and heterozygote TLR4 genotypes according to their $P$. gingivalis (P.g.) carriage. Significant differences between the groups are marked with $p$ values above the connector lines. Black dots indicate outliers

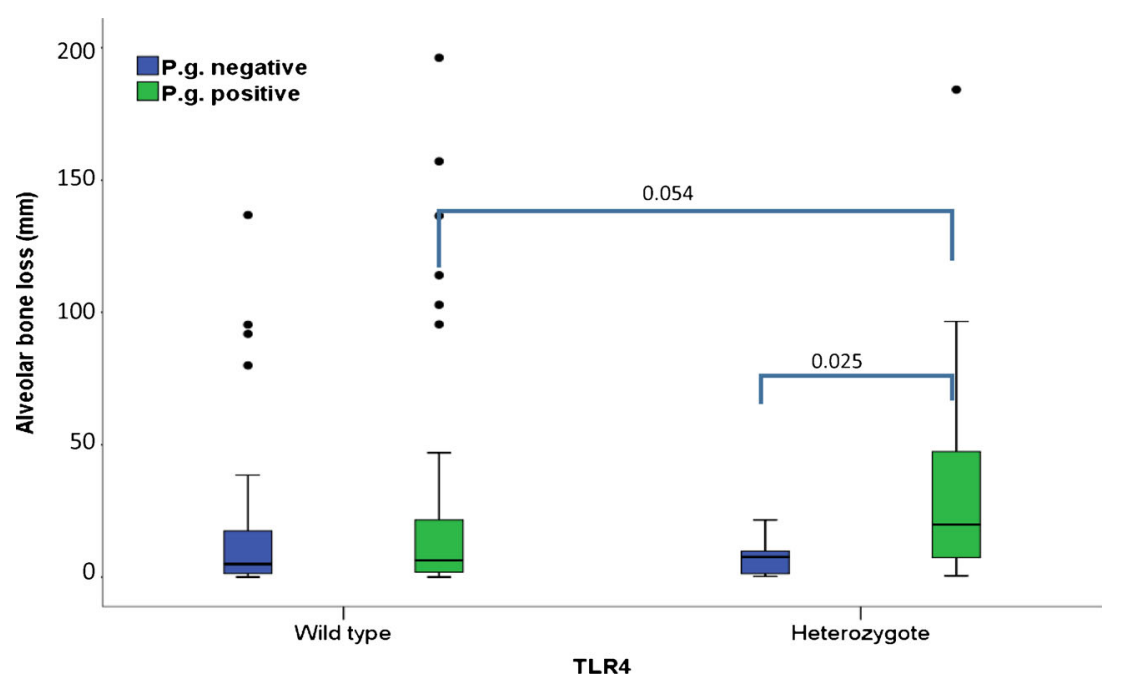

were measured from saliva. However, the use of alveolar bone loss had some shortcomings, such as distortion and missing information on buccal and palatal sides of the teeth. Yet, readily available panoramic radiographs serve more efficiently than clinical periodontal measurements in large population surveys for evaluating periodontal health. P. gingivalis carriage was determined by using stimulated salivary samples. It was recently demonstrated that in terms of bacterial profiles, stimulated and unstimulated saliva samples give comparable results [23]. Moreover, the use of saliva in detection of oral bacteria has superiority against that of plaque samples from a few subgingival sites, since in the latter case the absence of the target bacterium may indicate the absence of its colonization on the selected region, despite its presence elsewhere in the oral cavity [17]. Finally, the reliability of saliva in genetic studies in humans has been successfully demonstrated before [24].

In the present study, the TLR4 coding region Asp299Gly (rs4986790) was investigated. The frequency of TLR4
Asp299Gly polymorphism has been found to be $18 \%$ in another Finnish study population [18], which is close to our present finding (12.6\%). Previous reports on the associations of TLR4 Asp299Gly with periodontitis are controversial. A high [24] or low [25] periodontitis prevalence has been associated with TLR4 Asp299Gly SNP, while there are also studies showing no association between the TLR4 Asp299Gly SNP and periodontitis $[26,27]$. One explanation of the controversial results can be the simultaneous activation of TLR4 and TLR 2 by LPS. The cooperative function of these TLRs may hinder the dysfunction of TLR4. Another explanation can be the role of pathogenic bacteria in the initiation of periodontitis. It was previously demonstrated that subjects with TLR4 Asp299Gly SNP were more likely to be affected by osteomyelitis, a serious bone infection with an inflammatory character and relation to Gram-negative bacteria [28]. TLR4 heterozygous subjects may be prone to infection-induced inflammatory bone destruction, where specific Gram-negative pathogens are involved in initiating the disease process. A recent study
Fig. 3 Alveolar bone loss in subjects with wild type, heterozygote, and homozygote TLR9 genotypes according to their $P$. gingivalis (P.g.) carriage. A significant difference between the groups is marked with a $p$ value above the connector line. Empty circles indicate outliers

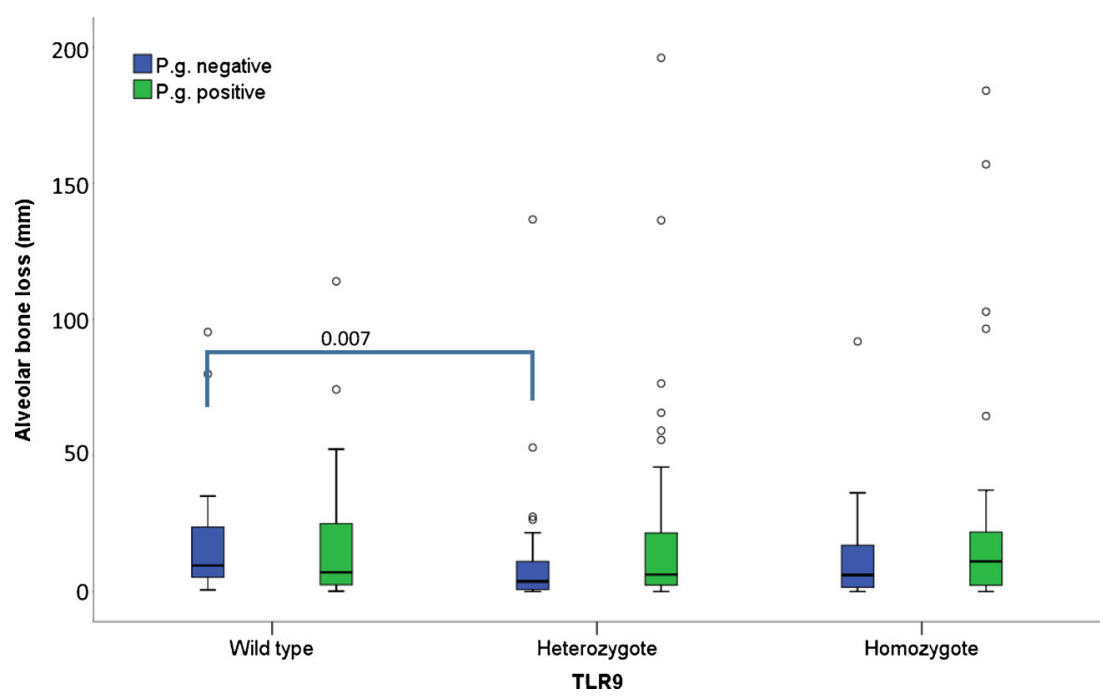


suggested that TLR4 Asp299Gly polymorphism is protective against chronic periodontitis in an American population [17]. According to their results, there is a negative interaction between the carriage of P. gingivalis and TLR4 Asp299Gly SNP. In a study on Dutch Caucasians, $P$. gingivalis showed an association between the CD14-260T/T genotype and periodontitis, while the frequency of the TLR4 299Asp>Gly gene polymorphism did not differ between the periodontitis and control groups [16]. Our findings are not in line with the results of these two studies. The contradiction can be attributed to the applied methods or ethnic background of the study populations; for example, the prevalence of TLR4 Asp299Gly SNP was $5.0 \%$ among Dutch periodontitis patients and controls, while it was $12.6 \%$ in the present Finnish study population.

TLR9 is an endosomal PRR and major sensor for microbial DNAs [14]. SNPs in the TLR9 gene have been related to the susceptibility to periodontitis, suggesting that TLR 9 plays a role in the pathogenesis of periodontitis $[29,30]$. In a recent study, where TLR9 knockout $\left(T L R 9^{-1}\right)$ and TLR9 wild type mice were infected with $P$. gingivalis, the TLR 9 knockout mice exhibited significantly less alveolar bone loss in comparison to the wild type mice [14]. In the present study, however, no significant difference was observed in alveolar bone loss between different TLR 9 genotype groups. Notably, $P$. gingivalis-negative individuals with TLR 9 heterozygotes had less alveolar bone loss than those with wild type. It can be speculated that in the absence of dysbiosis-regulating P. gingivalis, TLR9 could protect from alveolar bone loss. The SNP in TLR9 (rs187084) tested in the present study occurs in the promoter and affects the expression of the receptors. No information is available on the impact of this SNP on the pathogenesis of periodontitis; however, it functions as a susceptibility factor for rheumatoid arthritis [19].

In conclusion, the carriage of $P$. gingivalis in subjects with functional polymorphisms of TLR4 is related to alveolar bone loss, whereas polymorphisms of $T L R 9$ can be protective in the absence of $P$. gingivalis.

Compliance with ethical standards The authors report no conflicts of interest related to this study. This study was partly funded by the Finnish Dental Society Apollonia (UKG) and University of Turku joint research grant fund and the Academy of Finland (EK, PP). The study protocols have been approved by the Ethical Committee for Epidemiology and Public Health of the Hospital District of Helsinki and Uusimaa, Finland (407/E3/2000). All participants gave a written informed consent.

\section{References}

1. Kolenbrander PE, Palmer RJ Jr, Periasamy S, Jakubovics NS (2010) Oral multispecies biofilm development and the key role of cell-cell distance. Nat Rev Microbiol 8:471-480
2. Könönen E, Kumar P (2015) Bacteriology of periodontal diseases. In: Tangv YW, Sussman M, Liu D, Poxton I, Schwartzman J (eds) Molecular medical microbiology. Academic, Tokyo, pp 957-968

3. Zenobia C, Hajishengallis G (2015) Porphyromonas gingivalis virulence factors involved in subversion of leukocytes and microbial dysbiosis. Virulence 6:236-243

4. Maekawa T, Krauss JL, Abe T, Jotwani R, Triantafilou M, Triantafilou K, Hashim A, Hoch S, Curtis MA, Nussbaum G, Lambris JD, Hajishengallis G (2014) Porphyromonas gingivalis manipulates complement and TLR signaling to uncouple bacterial clearance from inflammation and promote dysbiosis. Cell Host Microb 15:768-778

5. Hajishengallis G (2015) Periodontitis: from microbial immune subversion to systemic inflammation. Nat Rev Immunol 15:30-44

6. Song B, Zhang Y, Chen L, Zhou T, Huang W, Zhou X, Shao L (2016) The role of toll-like receptors in periodontitis. Oral Dis. 2016 Feb 29. doi: 10.1111/odi.12468. [Epub ahead of print]

7. Beklen A, Hukkanen M, Richardson R, Konttinen YT (2008) Immunohistochemical localization of Toll-like receptors 1-10 in periodontitis. Oral Microbiol Immunol 23:425-431

8. Holden JA, Attard TJ, Laughton KM, Mansell A, O’Brien-Simpson NM, Reynolds EC (2014) Porphyromonas gingivalis lipopolysaccharide weakly activates M1 and M2 polarized mouse macrophages but induces inflammatory cytokines. Infect Immun 82:4190-4203

9. Li C, Li B, Dong Z, Gao L, He X, Liao L, Hu C, Wang Q, Jin Y (2014) Lipopolysaccharide differentially affects the osteogenic differentiation of periodontal ligament stem cells and bone marrow mesenchymal stem cells through Toll-like receptor 4 mediated nuclear factor $\mathrm{kB}$ pathway. Stem Cell Res Ther 5:67

10. Crump KE, Sahingur SE (2016) Microbial nucleic acid sensing in oral and systemic diseases. J Dent Res 95:17-25

11. Mori Y, Yoshimura A, Ukai T, Lien E, Espevik T, Hara Y (2003) Immunohistochemical localization of Toll-like receptors 2 and 4 in gingival tissue from patients with periodontitis. Oral Microbiol Immunol 18:54-58

12. Ribeiro FV, Santos VR, Bastos MF, De Miranda TS, Vieira AR, De Figueiredo LC, Duarte PM (2012) A preliminary study on the FAM5C expression in generalized chronic periodontitis. Oral Dis $18: 147-152$

13. Costalonga M, Batas L, Reich BJ (2009) Effects of Toll-like receptor 4 on Porphyromonas gingivalis-induced bone loss in mice. J Periodontal Res 44:537-542

14. Kim PD, Xia-Juan X, Crump KE, Abe T, Hajishengallis G, Sahingur SE (2015) Toll-like receptor 9-mediated inflammation triggers alveolar bone loss in experimental murine periodontitis. Infect Immun 83:2992-3002

15. Lin J, Bi L, Yu X, Kawai T, Taubman MA, Shen B, Han X (2014) Porphyromonas gingivalis exacerbates ligature-induced, RANKL-dependent alveolar bone resorption via differential regulation of Toll-like receptor 2 (TLR2) and TLR4. Infect Immun 82: 4127-4134

16. Laine ML, Morré SA, Murillo LS, van Winkelhoff AJ, Peña AS (2005) CD14 and TLR4 gene polymorphisms in adult periodontitis. J Dent Res 84:1042-1046

17. Sellers RM, Payne JB, Yu F, LeVan TD, Walker C, Mikuls TR (2016) TLR4 Asp299Gly polymorphism may be protective against chronic periodontitis. J Periodontal Res 51:203-211

18. Vuononvirta J, Toivonen L, Gröndahl-Yli-Hannuksela K, Barkoff AM, Lindholm L, Mertsola J, Peltola V, He Q (2011) Nasopharyngeal bacterial colonization and gene polymorphisms of mannose-binding lectin and toll-like receptors 2 and 4 in infants. PLoS One 6:e26198

19. Etem EO, Elyas H, Ozgocmen S, Yildırım A, Godekmerdan A (2011) The investigation of toll-like receptor 3, 9 and 10 gene polymorphisms in Turkish rheumatoid arthritis patients. Rheumatol Int 31:1369-1374 
20. Hyvärinen K, Laitinen S, Paju S, Hakala A, Suominen-Taipale L, Skurnik M, Könönen E, Pussinen PJ (2009) Detection and quantification of five major periodontal pathogens by single copy genebased real-time PCR. Innate Immun 15:195-204

21. Liljestrand JM, Gursoy UK, Hyvärinen K, Sorsa T, Suominen AL, Könönen E, Pussinen PJ (2014) Combining salivary pathogen and serum antibody levels improves their diagnostic ability in detection of periodontitis. J Periodontol 85:123-131

22. Gursoy UK, Könönen E, Huumonen S, Tervahartiala T, Pussinen PJ, Suominen AL, Sorsa T (2013) Salivary type I collagen degradation end-products and related matrix metalloproteinases in periodontitis. J Clin Periodontol 40:18-25

23. Belstrøm D, Holmstrup P, Bardow A, Kokaras A, Fiehn NE, Paster BJ (2016) Comparative analysis of bacterial profiles in unstimulated and stimulated saliva samples. J Oral Microbiol 8:30112

24. Schröder NW, Meister D, Wolff V, Christan C, Kaner D, Haban V, Purucker P, Hermann C, Moter A, Göbel UB, Schumann RR (2005) Chronic periodontal disease is associated with single-nucleotide polymorphisms of the human TLR-4 gene. Genes Immun 6:448-451

25. Garlet GP, Trombone AP, Menezes R, Letra A, Repeke CE, Vieira AE, Martins W Jr, Neves LT, Campanelli AP, Santos CF, Vieira AR (2012) The use of chronic gingivitis as reference status increases the power and odds of periodontitis genetic studies: a proposal based in the exposure concept and clearer resistance and susceptibility phenotypes definition. J Clin Periodontol 39:323-332

26. Berdeli A, Emingil G, Han Saygan B, Gürkan A, Atilla G, Köse T, Baylas H (2007) TLR2 Arg753Gly, TLR4 Asp299Gly and Thr399Ile gene polymorphisms are not associated with chronic periodontitis in a Turkish population. J Clin Periodontol 34:551-557

27. Izakovicova Holla L, Buckova D, Fassmann A, Roubalikova L, Vanek J (2007) Lack of association between chronic periodontitis and the Toll-like receptor 4 gene polymorphisms in a Czech population. J Periodontal Res 42:340-344

28. Montes AH, Asensi V, Alvarez V, Valle E, Ocaña MG, Meana A, Carton JA, Paz J, Fierer J, Celada A (2006) The Toll-like receptor 4 (Asp299Gly) polymorphism is a risk factor for Gram-negative and haematogenous osteomyelitis. Clin Exp Immunol 143:404-413

29. Sahingur SE, Xia XJ, Gunsolley J, Schenkein HA, Genco RJ, De Nardin E (2011) Single nucleotide polymorphisms of pattern recognition receptors and chronic periodontitis. J Periodontal Res 46:184-192

30. Holla LI, Vokurka J, Hrdlickova B, Augustin P, Fassmann A (2010) Association of Toll-like receptor 9 haplotypes with chronic periodontitis in Czech population. J Clin Periodontol 37:152-159 